\title{
Chronic exposure of honeybees, Apis mellifera (Hymenoptera: Apidae), to a pesticide mixture in realistic field exposure rates
}

\author{
Franziska BöHmE ${ }^{1}$, Gabriela BischofF ${ }^{2}$, Claus PW ZEBITz ${ }^{3}$, Peter RosenKranz ${ }^{1}$, \\ Klaus WALLneR ${ }^{1}$ \\ ${ }^{1}$ Apicultural State Institute, University of Hohenheim, August-von-Hartmann-Str. 13, 70599, Stuttgart, Germany
${ }^{2}$ Institute of Bee Protection, Julius Kühn-Institut, 14195, Berlin, Germany
${ }^{3}$ Applied Entomology, Institute of Phytomedicine, University of Hohenheim, 70599, Stuttgart, Germany
}

Received 16 June 2016 - Revised 14 September 2016 - Accepted 30 October 2016

\begin{abstract}
Pollen might be contaminated by multiple pesticides representing a risk for long-term contamination of honeybees when collected. Standardized methodology to assess the effects of pesticide mixtures under field conditions is lacking. We conducted an experiment on chronic feeding of a diet contaminated with a field-realistic pesticide mixture on free-flying honeybee colonies. Pesticide residues in larvae and adult tagmata were detected in trace amounts. In colonies treated with a pesticide mixture, larval weight was higher and acini diameters of the hypopharyngeal glands of nurse bees were smaller than in the untreated control. Brood termination and adult lifespan did not differ between both groups. Our study offers a reproducible and applicable approach for testing effects of pesticides on bee health. As feeding of a field-realistic pesticide mixture did not elicit acute bee toxic effects, the described differences might be explained by sub-lethal effects or joint action of single compounds.
\end{abstract}

pesticide combination / field test / long-term uptake / mini hives / multi-residue analysis

\section{INTRODUCTION}

The yield of various crops depends on pollination by bees, among which the honeybees (Apis mellifera Linnaeus 1758) are the most important pollinator species (Klein et al. 2007). However, the use of pesticides often coincides with honeybee activities in the crops. There are multiple routes for the exposure of foraging honeybees, either directly by spraying into the blossom (Koch and Weißer 1997), by dust from treated seeds (Schnier et al. 2003), by contaminated water

Electronic supplementary material The online version of this article (doi:10.1007/s13592-016-0479-x) contains supplementary material, which is available to authorized users.

Corresponding author: F. Böhme, franziska.boehme@uni-hohenheim.de Manuscript editor: Monique Gauthier puddles (Samson-Robert et al. 2014), or by inhalation of volatilized pesticides (Geoghegan et al. 2013) or indirectly by accumulation of compounds in nectar, pollen, and guttation droplets (Kubik et al. 1999, Girolami et al. 2009).

Against this background, the uptake of pesticides by foraging bees into the hive and the contamination of food storage is obvious and might cause long-term effects on colony development (Mullin et al. 2010). Mainly, the pollen-stored as bee bread - often contains a mixture of various chemical compounds, usually in trace concentrations (Chauzat et al. 2006; Mullin et al. 2010; Rosenkranz et al. 2013).

Although there might be no acute insecticidal effect through such contaminations, various pesticides taken up in sub-lethal concentrations are considered to have negative effects on learning, foraging behavior, or development of individual honeybees 
(Thompson 2003; Aliouane et al. 2009; Dai et al. 2010; Wu et al. 2011; Williamson et al. 2013; Fischer et al. 2014; Urlacher et al. 2016). Additionally, investigations of mixtures of some active substances have confirmed joint actions by additive and/or synergistic effects on physiological processes, often increasing the susceptibility to single pesticides in a pesticide mixture (Pilling et al. 1995; Gill et al. 2012).

Finally, only few studies addressed the effects of chronic pesticide uptake, most of them only as in vitro studies (Dechaume Moncharmont et al. 2003; Human et al. 2014).

In this study, we present a methodological approach that so far has not been used for testing the effects of a chronic exposure of pesticide mixtures on the colony level. Thereby, we utilized the advantages of laboratory cage tests as a targeted application of pesticides to individually marked bees but kept the test population under realistic field conditions within a small free-flying and queenright colony. Here, we tested both the effects on larval and imaginal development during and after chronic uptake of a pesticide mixture in realistic field exposure rates. A pesticide residue analysis of pollen loads, collected daily from pollen traps in an intensively used agricultural area, served to define (i) the substances and (ii) the concentrations of the pesticide mixture for the experiment.

\section{MATERIALS AND METHODS}

\subsection{Analysis of field-collected pollen and preparation of artificially pesticide contaminated pollen diets}

Pollen traps were set up in spring (March-July) 2012, as part of a long-term pollen survey, on honeybee colonies situated in a typical agricultural region in Southern Germany characterized by high amounts of conventionally farmed corn and oilseed rape fields. Pollen pellets were collected daily and stored at $-20{ }^{\circ} \mathrm{C}$ for residue analysis. The highest concentrations of 12 pesticides in spring samples were taken as orientation values to create the pesticide mixture in the feeding experiment in 2014 (Online Resource 1, Table S-I). Pesticides used in rapeseed production but found only in traces below the limit of quantification (LOQ) (azoxystrobin, prosulfocarb, pyraclostrobin, and tau- fluvalinate) were considered in their respective concentration at limit of detection (LOD).

An artificial pollen-honey diet was prepared as a mixture of pesticide-free commercially available willow pollen pellets (Andreas Bock, Ökologische Imkerei, Mertingen, Germany), finely ground with a centrifugal mill and mixed with creamy honey (harvested at the Apicultural State Institute in spring 2014), in a kneading machine at a ratio of 40:60 \% w/w. The test pesticides (commercial products in their respective formulation) were diluted in tap water 1:100, added to the honey in the necessary amounts to achieve the respective final concentration in the pollen diet, and thoroughly homogenized before mixing with the pollen (Table I and Online Resource 1, Table S-II).

\subsection{Bee colonies and experimental design}

Twelve colonies of A. mellifera carnica were set up in polystyrene mini hives $(29 \times 29 \times 32 \mathrm{~cm}$ LWH) in July 2014. Each hive consisted of six frames with a residue-free wax foundation, colonized by approx. 2500 worker bees and one queen. Free mated sister queens of the year 2014 were used and caged on an empty frame at $8 \mathrm{p} . \mathrm{m}$. for $24 \mathrm{~h}$ (start of the experiment $=$ day 1$)$ to obtain larvae of defined age. Because one queen of a control hive did not oviposit, only three replicates were left in this group. Sampling took place always at 8 a.m. at any observation date, causing an age difference of $\pm 12 \mathrm{~h}$ of larvae and bees.

The colonies were treated as follows: (1) pollen-honey diet with the pesticide mixture $(n=4)$; (2) pure pollen-honey diet (control, $n=3$ ); and (3) pollen-honey diet mixed with fenoxycarb (toxic reference, $n=4$ ). Fenoxycarb as an insect growth regulator is commonly used as a toxic control in tests on side effects of pesticides in bees (OECD 2007). Fifty-gram packages of the respective diets were offered 1 day after start of the experiment to let the pesticides circulate in the colony while the brood was in the egg stage. When larvae hatched 2 days later, food packages were replaced three times until the cells were capped at day 9. Feeding was continued in the second period when worker bees had hatched from the capped cells for an additional 7 days. The exact amount of consumed pollen-honey diet was assessed daily using a portable balance. From 
Table I. Pesticide concentrations $(\mu \mathrm{g} / \mathrm{kg})$ in the artificial bee bread used in the feeding experiment.

\begin{tabular}{|c|c|c|}
\hline & Active compound & Concentration of compounds in pollen-honey diet $(\mu \mathrm{g} / \mathrm{kg})$ \\
\hline \multirow[t]{4}{*}{ Control } & Azoxystrobin $^{\mathrm{a}}$ & 1.3 \\
\hline & Carbendazim $^{\mathrm{a}}$ & 0.4 \\
\hline & Prosulfocarb ${ }^{a}$ & 0.7 \\
\hline & Thiacloprid $^{\mathrm{a}}$ & 16.0 \\
\hline \multirow[t]{13}{*}{ Pesticide mixture } & Acetamiprid & 28.7 \\
\hline & Azoxystrobin & 1.9 \\
\hline & Boscalid & 21.6 \\
\hline & Carbendazim $^{\mathrm{a}}$ & 0.4 \\
\hline & Dimethenamid-P & 6.0 \\
\hline & Dimoxystrobin & 24.3 \\
\hline & Methiocarb & 46.0 \\
\hline & Prosulfocarb & 2.5 \\
\hline & Pyraclostrobin & 0.2 \\
\hline & Tau-fluvalinate & 1.0 \\
\hline & Tebuconazole & 33.2 \\
\hline & Thiacloprid & 243.4 \\
\hline & Triadimenol & 16.5 \\
\hline \multirow[t]{3}{*}{ Toxic reference } & Fenoxycarb & 2137 \\
\hline & Azoxystrobin $^{\mathrm{a}}$ & 1.3 \\
\hline & Thiacloprid $^{\mathrm{a}}$ & 10.8 \\
\hline
\end{tabular}

${ }^{\mathrm{a}}$ Substances derived from the polyfloral honey and are not added purposely for the experiment

colony formation until the end of the experiment, sugar paste (Apifonda ${ }^{\circledR}$ ) was offered ad libitum to all colonies. To reduce the dilution of the pesticides by freshly collected pollen, a grid was placed at the hive entrance to scrape the pollen loads of foragers. To prevent effects through varroosis, each hive was equipped with one strip of the commonly used acaricide Bayvarol ${ }^{\circledR}(4 \mathrm{mg}$ flumethrin). By using a synthetic acaricide, we tried to set up realistic conditions, as honeybees get into contact with both crop protection pesticides and acaricides used by beekeepers.

All colonies were placed at a yard of the apicultural state institute in Hohenheim in a randomized block design.

\subsection{Brood development assessment and brood termination rate}

Brood development assessment was done according to the method described by Schur et al. (2003). After releasing the queen from the cage, the position of eggs at day 2 (brood fixing day) was marked on transparent sheets. Development of the brood was assessed at four successive dates $(+5 /+10 /+16 /+22( \pm 1$ day each $)$ days after brood fixing day).

To calculate the brood termination rate (BTR), the brood was categorized by expected developmental stage reached (= successful development) or expected stage not reached (= brood terminated). According to the number of available brood cells, at least 133 cells per colony were analyzed. BTR for each treatment was then calculated as mean of the respective colonies.

\subsection{Larval weight determination}

Two days after cell capping, the brood cells were opened and at least ten larvae in the pre-pupal stage of each colony were randomly taken for individual fresh weight assessment. Immediately after weighing, the larvae of each colony were pooled, frozen, and kept at $-20{ }^{\circ} \mathrm{C}$ for later residue analysis. 


\subsection{Color coding of bees and lifespan evaluation}

Two days before emergence of adult bees from the marked cells, frames of each colony were put into cages and kept within an incubator $\left(35^{\circ} \mathrm{C}\right)$ until hatching. Freshly emerged bees of each colony were tagged with numbered Opalith platelets on their thorax. After coding, the bees were reintroduced into their respective colonies. For 33 days, the presence of tagged bees was observed in 2-day intervals to determine the lifespan of each bee.

\subsection{Preparation and size determination of the hypopharyngeal glands of nurse bees}

Five six-day old color-coded bees of each colony were sampled, anesthetized, for $2 \mathrm{~min}$ in the freezer, and then decapitated. The heads were dissected, and hypopharyngeal glands were pulled out and placed on a microscope slide without a cover glass but with a drop of insect saline solution (Carreck et al. 2013). Diameters of 10 acini parallel to the axial duct per bee were measured under a microscope at a magnification of $\times 100$ (Moritz and Crailsheim 1987).

\subsection{Pesticide residue analysis}

The following samples were analyzed:

1. Pollen pellets from colonies at an intensive agricultural site (see Sect. 2.1) to identify field realistic residue pattern. Analysis were performed at the LUFA Speyer by a multi-residue (282 substances) QuEChERS approach (Anastassiades et al. 2003)

2. A sample of the pollen-honey diet from each treatment group

3. Eight-day old larvae (see Sect. 2.4), pooled per colony, to assess the pesticide content after the first period of feeding the diet

4. Six-day old nurse bees from each colony (9-10 each, pooled per colony) subdivided into head, thorax, and abdomen

Analyses of samples 2-4 were done at the Julius Kühn-Institut, Berlin. Detailed method and equipment description are given in Online Resource 2.

\subsection{Statistical analysis}

Data were analyzed using the computer software JMP® 11.1.1 (SAS Institute Inc., Cary, NC, USA) and IBM SPSS Statistics 22 (IBM, Armonk, NY, USA).

Parametric data, i.e., larval weight, acini diameter, and lifespan, were analyzed by the following steps: (i) generalized linear model (GLM procedure) and (ii) oneway ANOVA with subsequent Tukey-Kramer HSD test at $\alpha=0.05$, to compare the effects of independent parameters. $F, d f$, and $P$ values were corrected by Welsh test if variance inhomogeneity was given following Bartlett's test.

BTR data were analyzed by a nonparametric Kruskal-Wallis test followed by a Wilcoxon pairwise comparison at $\alpha=0.05$.

A Kaplan-Meier analysis was performed to test for effects of treatments on adult survival against time. Seventy-five, 50, and $25 \%$ survival probability was calculated from the Weibull distribution of survival.

\section{RESULTS}

\subsection{Pesticide intake into colonies}

Based on the pesticide concentrations in the diet (Table I) and the daily consumption, the total quantity of pesticides introduced into each colony was calculated. On average, colonies in the pesticide group ingested 56.6 and $38.2 \mu \mathrm{g}$ of the pesticide mixture during larval development and as nurse bees, respectively. In the toxic reference group, the mean amount of fenoxycarb consumed was $192.8 \mu \mathrm{g}$ for larvae and $196.6 \mu \mathrm{g}$ for nurse bees (Table II).

\subsection{Effect on larval weight, brood termination rate, and acini diameter of hypopharyngeal glands}

The average larval weight of the control group (140.7 mg) was significantly lower compared to the pesticide or fenoxycarb group, both with a larval weight higher than $145 \mathrm{mg}$ (Table III).

Brood termination was not significantly different between the untreated control $(15.9 \%)$ and the pesticide group $(26.3 \%)$. Yet, BTR was significantly higher in the positive control colonies compared to both other groups. In these colonies, more 
Table II. Amount of consumed pollen-honey diet (g, means \pm SD) for the first (larval) and second (adult) feeding period, and calculated amount of pesticide intake $(\mu \mathrm{g})$.

Control

\begin{tabular}{lll}
\hline & Larvae & Adults \\
Total amount of consumed pollen-honey diet $(\mathrm{g})$ & $126.93 \pm 5.93$ & $93.33 \pm 4.29$ \\
Azoxystrobin & $0.17 \pm 0.01$ & $0.12 \pm 0.01$ \\
Prosulfocarb & $0.09 \pm 0.00$ & $0.07 \pm 0.00$ \\
Thiacloprid & $2.03 \pm 0.09$ & $1.49 \pm 0.07$ \\
Total Pesticide amount $(\mu \mathrm{g})$ & $2.28 \pm 0.11$ & $1.68 \pm 0.08$ \\
& Pesticide mixture & \\
& Larvae & Adults \\
Total amount of consumed pollen-honey diet $(\mathrm{g})$ & $132.91 \pm 15.61$ & $89.61 \pm 11.40$ \\
& Calculated amount of pesticides incorporated into colonies via pollen- \\
& honey diet $(\mu \mathrm{g})$ & \\
Acetamiprid & $3.81 \pm 0.33$ & $2.57 \pm 0.33$ \\
Azoxystrobin & $0.25 \pm 0.02$ & $0.17 \pm 0.02$ \\
Boscalid & $2.87 \pm 0.25$ & $1.94 \pm 0.25$ \\
Dimethenamid-P & $0.80 \pm 0.07$ & $0.54 \pm 0.07$ \\
Dimoxystrobin & $3.23 \pm 0.28$ & $2.18 \pm 0.28$ \\
Methiocarb & $6.11 \pm 0.52$ & $4.12 \pm 0.52$ \\
Prosulfocarb & $0.33 \pm 0.03$ & $0.22 \pm 0.03$ \\
Pyraclostrobin & $0.03 \pm 0.00$ & $0.02 \pm 0.00$ \\
Tau-Fluvalinate & $0.13 \pm 0.01$ & $0.09 \pm 0.01$ \\
Tebuconazole & $4.41 \pm 0.38$ & $2.98 \pm 0.38$ \\
Thiacloprid & $32.35 \pm 2.77$ & $21.81 \pm 0.77$ \\
Triadimenol & $2.19 \pm 0.19$ & $1.48 \pm 0.19$ \\
Total pesticide amount $(\mu \mathrm{g})$ & $56.58 \pm 6.65$ & $38.15 \pm 4.85$ \\
Total amount of consumed pollen-honey diet $(\mathrm{g})$ & $90.20 \pm 9.45$ & \\
& Calculated amount of pesticides incorporated into colonies via pollen- \\
Fenoxycarb & $192.75 \pm 20.20$ & \\
\hline & & \\
& & \\
& & \\
& &
\end{tabular}

than $50 \%$ of the marked larvae died before hatching (Table III).

Acini diameters of the pesticide-fed colonies $(125.2 \mu \mathrm{m})$ were significantly smaller than those of the control $(133.3 \mu \mathrm{m})$, but significantly bigger than those in the toxic reference $(120.0 \mu \mathrm{m}$; Table III).

\subsection{Survival analysis of adult bees}

The median survival time, meaning the time half of the individuals have died, was considerably longer in the pesticide mixture group and the control group, with 27 and 29 days respectively, compared to the toxic reference group (5 days). However, no significant differences could be observed between the untreated control and the pesticide-treated group (Table IV and Online Resource 3).

\subsection{Residue analysis of larvae and nurse bees}

Five of the experimental substances (azoxystrobin, dimoxystrobin, fenoxycarb, tau- 
Table III. Effect of treatments on (i) weight (mg) of 8-day old larvae, (ii) brood termination rate (\%), based on four brood assessment dates, and (iii) acini diameter $(\mu \mathrm{m})$ of hypopharyngeal glands of 6-day old nurse bees; each given as mean \pm SE. Each endpoint is indicated with statistical analysis.

\begin{tabular}{lccc}
\hline Treatment group & Larval weight $(\mathrm{mg})^{\mathrm{a}}$ & ${\text { Brood termination rate }(\%)^{\mathrm{b}}}^{\mathrm{b}}$ & ${\text { Acini diameter }(\mu \mathrm{m})^{\mathrm{a}}}^{\mathrm{a}}$ \\
\hline Control & $140.73 \pm 1.03 \mathrm{~b} n=37$ & $15.9 \pm 2.46 \mathrm{~b} n=3$ & $133.3 \pm 1.58 \mathrm{a} n=150$ \\
Pesticides & $146.17 \pm 0.75 \mathrm{a} n=48$ & $26.3 \pm 7.62 \mathrm{~b} n=4$ & $125.2 \pm 1.36 \mathrm{~b} n=200$ \\
Tox. reference & $147.30 \pm 0.60 \mathrm{a} n=50$ & $51.7 \pm 9.08 \mathrm{a} n=4$ & $120.0 \pm 1.34 \mathrm{c} n=200$ \\
& $F=18.6607$ & $\chi^{2}=6.5202$ & $F=20.8710$ \\
$d f$ & 2 & 2 & 2 \\
$p$ & $<0.0001$ & 0.0384 & $<0.0001$ \\
\hline
\end{tabular}

${ }^{\text {a }}$ Means followed by common letters do not differ at $\alpha=0.05$, Tukey-Kramer HSD test

${ }^{\mathrm{b}}$ Means followed by common letters do not differ at $\alpha=0.05$ by Kruskal-Wallis test

fluvalinate, thiacloprid) and flumethrin were occasionally identified in the residue analysis of larvae or bees. With the exception of azoxystrobin, fenoxycarb, and flumethrin, all compounds were found only in trace amounts below LOQ. Dimoxystrobin and thiacloprid were only detected in the pesticide group; the other compounds were present at least once in all three experimental groups (see Online Resource 4, Table S-III for details).

\section{DISCUSSION}

Although requested by scientists and beekeepers, the effect of pesticide mixtures in sub-lethal concentrations to honeybee colonies under field conditions has not properly been assessed yet (Mullin et al. 2010; Sanchez-Bayo and Goka 2014). In this study, we present a new and applicable approach to test effects of pesticide mixtures on free-flying honeybee

Table IV. Survival analysis showing the total number of color-coded bees, the number of censored individuals, lifespan (days) (mean $\pm \mathrm{SE}$ ), median lifespan (days), and the 75, 50, and $25 \%$ survival probability for each group.

\begin{tabular}{|c|c|c|c|c|c|c|}
\hline \multirow{2}{*}{$\begin{array}{l}\text { Treatment } \\
\text { group }\end{array}$} & \multirow{2}{*}{$\begin{array}{l}\text { Total } \\
\text { number }\end{array}$} & \multirow{2}{*}{$\begin{array}{l}\text { Number } \\
\text { censored }\end{array}$} & \multirow[t]{2}{*}{ Mean $\pm \mathrm{SE}$} & \multirow{2}{*}{$\begin{array}{l}\text { Median lifespan } \\
\text { (days) }\end{array}$} & \multicolumn{2}{|c|}{ Probability of } \\
\hline & & & & & $\begin{array}{l}\text { Survival } \\
(\%)\end{array}$ & $\begin{array}{l}\text { At time } \\
\text { (days) }\end{array}$ \\
\hline \multirow[t]{3}{*}{ Control } & 161 & 53 & $25.56 \pm 0.668 \mathrm{a}$ & 29 & 0.75 & 19.52 \\
\hline & & & & & 0.50 & 27.17 \\
\hline & & & & & 0.25 & 35.27 \\
\hline \multirow[t]{3}{*}{ Pesticides } & 187 & 44 & $24.60 \pm 0.659 \mathrm{a}$ & 27 & 0.75 & 17.64 \\
\hline & & & & & 0.50 & 25.28 \\
\hline & & & & & 0.25 & 33.58 \\
\hline \multirow[t]{3}{*}{ Tox. reference } & 135 & 7 & $6.87 \pm 0.593 b$ & 5 & 0.75 & 2.59 \\
\hline & & & & & 0.50 & 5.44 \\
\hline & & & & & 0.25 & 9.74 \\
\hline$F$ & & & 234.4866 & & & \\
\hline$d f$ & & & 2,480 & & & \\
\hline$p$ & & & $<0.0001$ & & & \\
\hline
\end{tabular}

Means followed by common letters do not differ at $\alpha=0.05$, Tukey-Kramer HSD test 
colonies. Here, we fed a mixture of pesticides commonly found in pollen samples of colonies with access to areas with intensive oilseed rape and corn production. Each compound was used in sub-lethal concentrations based on the maximum values quantified in residue analysis during the flowering period of the crops. We offered the substances during the complete preimaginal developmental period and during the first week of imaginal development to imitate a chronic exposure inside the hive. This method allows the analysis of pesticide effects on individual bees that could develop and perform their social tasks under natural colony conditions. As the combination of plant protection products change during the season and between different agricultural areas, we are aware of the fact that our experiment is only an approximation to general field-realistic conditions (Rosenkranz et al. 2013).

Fairly high residue concentrations of the toxic reference fenoxycarb confirmed the successful uptake of the pesticides in larvae and in adult bees and validate our experimental approach. Fenoxycarb is considered a particularly suitable standard as it affects larvae and adults as well. High rates of brood termination, decreased size of hypopharyngeal glands in nurse bees, precocious foraging, and a shortened lifespan were found, previously described as typical intoxication symptoms caused by juvenile hormone analogs (Rutz et al. 1976; Robinson 1985; de Ruijter and van der Steen 1987; Tasei 2001).

Six of the experimental substances were occasionally identified in the residue analysis in larvae and nurse bee tagmata; however, only azoxystrobin, fenoxycarb, and flumethrin were above the LOQ.

An unexpected trace contamination of fenoxycarb was found in larvae of the untreated control and the pesticides group, but in 140- and 340 -fold lower concentrations. This may be due to some individual erratic or robbing bees bringing back contaminated food from other colonies. As expected, the use of a synthetic acaricide to prevent mite infestation could also be identified in the residue analysis. Flumethrin as the active substance was found only in the abdomen of adult bees, presumably from the contamination of the abdominal surface of those bees during contact with the Bayvarol ${ }^{\circledR}$ strip. However, to quit the mite control would have an uncontrollable impact on experimental colonies. Even a low mite infestation in combination with associated infections of honeybee viruses has significant effects on the lifespan and physiological health parameters of the host bees (Dainat et al. 2012). The use of a highly efficient mite treatment throughout the complete experimental period is therefore an indispensable requirement if free-flying colonies are used.

A further source of traces of fungicides (azoxystrobin, carbendazim) and one insecticide (thiacloprid) in the treatment and control pollenhoney diet was the polyfloral honey used in the diet, containing also rapeseed components. Although this honey was considered pesticide free, it contained a reasonable proportion of these typical rapeseed pesticides. But it should be emphasized that the bees of the pesticide group were fed with a worst-case concentration of a field-realistic pesticide mixture over the whole life cycle creating a substantial difference in pesticide application compared to the control bees. However, for future tests, a different kind of honey such as honeydew honey with unlikely contact to pesticides may serve better to form artificial bee bread. In the case of trace residues of azoxystrobin in the control group, it is likely that foraging bees collect contaminated nectar or pollen. Even by using a pollen grid, the intake of pollen cannot be completely excluded. Azoxystrobin is a very commonly used fungicide that is frequently used by farmers and private users in different crops and ornamental plants. Generally, our data provide no evidence for bioaccumulation of any substance in the pesticide mixture and concentrations offered, even after chronic feeding.

A direct comparison of our residue data with those from other studies is rather difficult, as most of the studies subject their analysis to bee samples from colonies in intensively used agricultural areas, poisoning incidents or analysis of only a few substances (Chauzat et al. 2009; van Engelsdorp et al. 2009; Mullin et al. 2010; Pareja et al. 2011; Wiest et al. 2011; Kasiotis et al. 2014; Codling et al. 2016; Hladik et al. 2016). Furthermore, none of them were conducted under similar experimental approaches with chronic feeding of a pesticide mixture.

Larvae and bees treated chronically with fieldrealistic concentration of our pesticide mixture did 
not reveal measurable bee toxic effects, not even after ingestion of the most toxic substance of our mixture, methiocarb. Both brood termination (BTR) and average lifespan of worker bees were not significantly affected by the treatment compared to control bees. The measured lifespan here reflects the average lifespan of worker summer bees of 30-40 days (Winston et al. 1981). Consequently, from these results, we would not expect that the colony development and population size are negatively affected by an increased mortality.

However, we observed significant differences within two physiological endpoints that may indicate sub-lethal effects of the pesticide mixture at the individual bee level.

One physiological endpoint recorded was the larval weight 2 days after the capping of the brood cell. Larvae from the pesticide group had a significantly higher fresh biomass than the control, although with a relatively low difference of only $4 \%$ between the two groups. Despite the sometimes high variance in larval weight found by several authors (Babendreier et al. 2004; Hrassnigg and Crailsheim 2005), the differences found in our experiments are considered reliable because of a very low variance within the treatments. This unexpected weight difference may be explained by a pesticide-induced slight delay of larval development. This putative positive effect on weight during larval development is consistent with results of a recently published experiment where the sub-lethal application of a pesticide to honeybee queen larvae caused an increase of the number of ovarioles in the hatching queen. Also, this phenomenon could not satisfactorily be explained by the authors (Williams et al. 2015). Generally, impacts of pesticides on honeybee larvae are poorly understood so far (Human et al. 2014).

The second endpoint that showed significant differences was the acini diameter of hypopharyngeal glands in nurse bees, which was significantly smaller in the pesticide treatments compared to the control. In our experiment, the average acini size of the control bees was somewhat smaller than that reported by Deseyn and Billen (2005). This might be due to the fact that we used 6-day-old bees where the acini had not developed yet to their full size. However, as we used exactly the same age for both groups, the about $6 \%$ reduced size in the pesticide-treated bees has likely been caused by the treatment and might indicate a pesticide-induced delay of growth. This is in accordance with Hatjina et al. (2013) who reported similar effects after ingestion of sub-lethal concentrations of imidacloprid and Heylen et al. (2011) who recorded similar effects even after an only 24-h application of food contaminated with different pesticides. The effect of smaller hypopharyngeal glands on the colony development can only be estimated. Hatjina et al. (2013) assumed that acini of smaller size interfere with the production of jelly and might additionally speed up the shift from nurse to foraging bees. The latter could reduce the percentage of nurse bees in a honeybee colony and subsequently lead to a decline of the colony size.

We can only speculate whether synergistic and/ or additive effects were responsible for the potential delay of growth or maturing processes causing differences in larval weight and the size of hypopharyngeal glands, respectively. For instance, synergistic effects have been confirmed for a combination of ergosterol-biosynthesis-inhibiting (EBI) fungicide and a pyrethroid insecticide (Pillings et al. 1995) or neonicotinoids (Iwasa et al. 2004; Thompson et al. 2014) and additive effects for a combination of neonicotinoids and pyrethroids (Gill et al. 2012). In the study at hand, we have a combined exposure of EBI fungicides (tebuconazole, triadimenol), pyrethroid insecticides (tau-fluvalinate, flumethrin), and neonicotinoid insecticides (acetamiprid, thiacloprid). However, it seems impossible to analyze for a mixture with 12 pesticides the possible additive and synergistic effects, even more under the conditions of chronic exposure. In view of this fact, our approach offers anyway a feasible option to perform a fieldrealistic risk assessment. For this purpose, one has (i) to analyze the worst-case contamination of the honeybee colony in a certain region and (ii) use these pesticides in the respective composition for a chronic application in free-flying mini hives.

However, there are still some constraints associated with this approach. So it is nearly impossible to ensure completely residue-free controls over the whole experimental period. Trace contamination of controls can occur by (i) previously contaminated food, (ii) robbing from neighboring treated colonies, and (iii) foraging from treated crops. Thus, controls 
without any pesticide residues are hardly possible when free-flying colonies are used. To minimize the contamination via nectar intake, the tests with the mini hives should be performed far from agricultural used sites.

Nevertheless, the use of free-flying colonies avoids negative semi-field and cage effects (Schur et al. 2003; Pistorius et al. 2011) and our approach represents currently the only option to evaluate longterm effects of pesticide mixtures under field realistic conditions. Yet, such methods are essential in terms of prohibition or re-registration of pesticides.

\section{ACKNOWLEDGMENTS}

The authors are grateful to Dr. Dieter Martens from LUFA Speyer for the analyses of the pollen pellets. Special thanks are given to Kerstin Jänicke and Hartmut Nowak for their contribution to the residue analysis of the pollen-honey diet, larvae, and nurse bees at Julius Kühn-Institute, Berlin.

Authors' contributions FB performed the experiment. $\mathrm{FB}, \mathrm{KW}$ designed the experimental setup, FB, KW, CPWZ analyzed the data, FB, KW, CPWZ, PR wrote the manuscript, GB performed residue analysis

\section{OPEN ACCESS}

This article is distributed under the terms of the Creative Commons Attribution 4.0 International License (http://creativecommons.org/licenses/by/4.0/), which permits unrestricted use, distribution, and reproduction in any medium, provided you give appropriate credit to the original author(s) and the source, provide a link to the Creative Commons license, and indicate if changes were made.

Exposition chronique d'abeilles, Apis mellifera (Hymenoptera: Apidae), à un mélange de pesticides correspondant à des taux réalistes d'exposition en champ

Combinaison de pesticides/ test en champ/ consommation à long-terme/ mini colonies/ analyse multi-résidus

Chronische Fütterung von Honigbienen, Apis mellifera ( Hym enoptera: A pidae), mit e inem Pflanzenschutzmittelgemisch in feld-realistischen Konzentrationen.
Pestizid Kombination/ Freilandversuch/ Langzeitversuch/ Mini-Völker/ Rückstandsanalyse

\section{REFERENCES}

Aliouane, Y., El Hassani, A.K., Gary, V., Armengaud, C., Lambin, M., Gauthier, M. (2009) Subchronic exposure of honeybees to sublethal doses of pesticides: Effects on behavior. Environ. Toxicol. Chem. 28(1), 113-122

Anastassiades, M., Lehotay, S.J., Stajnbaher, D., Schenck, F.J. (2003) Fast and easy multiresidue method employing acetonitrile extraction/partitioning and "dispersive solid-phase extraction" for the determination of pesticide residues in produce. J. AOAC Int. 86 (2), 412-431

Babendreier, D., Kalberer, N., Romeis, J., Fluri, P., Bigler, F. (2004) Pollen consumption in honey bee larvae: A step forward in the risk assessment of transgenic plants. Apidologie 35, 293-300

Carreck, N.L., Andree, M., Brent, C.S., Cox-Foster, D., Dade, H.A., et al. (2013) Standard methods for Apis mellifera anatomy and dissection. J. Apic. Res. 52 (4), $1-40$

Chauzat, M.-P., Carpentier, P., Martel, A.-C., Bougeard, S., Cougoule, N., et al. (2009) Influence of pesticide residues on honey bee (Hymenoptera: Apidae) colony health in France. Environ. Entomol. 38 (3), 514-523

Chauzat, M.-P., Faucon, J., Martel, A., Cougoule, N., Aubert, M., et al. (2006) A survey of pesticide residues in pollen loads collected by honey bees in France. J. Econ. Entomol. 99 (2), 253-262

Codling, G., Al Naggar, Y., Giesy, J.P., Robertson, A.J. (2016) Concentrations of neonicotinoid insecticides in honey, pollen and honey bees (Apis mellifera L.) in central Saskatchewan, Canada. Chemosphere 144, 2321-2328

Dai, P.L., Wang, Q., Sun, J.H, Liu, F., Wang, X., et al. (2010) Effects of sublethal concentrations of bifenthrin and deltamethrin on fecundity, growth, and development of the honeybee Apis mellifera ligustica. Environ. Toxicol. Chem. 29(3), 644-649

Dainat, B., Evans, J.D., Chen, Y.P., Gauthier, L., Neumanna, P. (2012) Dead or alive: Deformed wing virus and Varroa destructor reduce the life span of winter honeybees. Appl. Environ. Microbiol. 78(4), 981-987

de Ruijter, A., van der Steen, J. (1987) Feldversuche zum Effekt einer Insegar (Fenoxycarb)- Spritzung während der Apfelblüte auf die Honigbiene. Apidologie 18(4), 355-357

Dechaume Moncharmont, F.-X., Decourtye, A., Hennequet-Hantier, C., Pons, O., Pham-Delègue, M.H. (2003) Statistical analysis of honeybee survival after chronic exposure to insecticides. Environ. Toxicol. Chem. 22 (12), 3088-3094

Deseyn, J., Billen, J. (2005) Age-dependent morphology and ultrastructure of the hypopharyngeal gland of Apis 
mellifera workers (Hymenoptera, Apidae). Apidologie 36, 49-57

Fischer, J., Müller, T., Spatz, A.K., Greggers, U., Grünewald, B., Menzel, R. (2014) Neonicotinoids interfere with specific components of navigation in honeybees. PLoS One 9(3), 1-10

Geoghegan, T., Kimberly, J., Scheringer, M. (2013) Predicting honeybee exposure to pesticides from vapour drift using a combined pesticide emission and atmospheric transport model. SETAC Australasia - Multidisciplinary approaches to managing environmental pollution. p.174

Gill, R.J., Ramos-Rodriguez, O., Raine, N.E. (2012) Combined pesticide exposure severely affects individualand colony-level traits in bees. Nature 491 (7422), 105-108

Girolami, V., Mazzon, L., Squartini, A., Mori, N., Marzaro, M., et al. (2009) Translocation of neonicotinoid insecticides from coated seeds to seedling guttation drops: A novel way of intoxication for bees. J. Econ. Entomol. 102 (5), 1808-1815

Hatjina, F., Papaefthimiou, C., Charistos, L., Dogaroglu, T., Bouga, M., et al. (2013) Sublethal doses of imidacloprid decreased size of hypopharyngeal glands and respiratory rhythm of honeybees in vivo. Apidologie 44 (4), 467-480

Heylen, K., Gobin, B., Arckens, L., Huybrechts, R., Billen, J. (2011) The effects of four crop protection products on the morphology and ultrastructure of the hypopharyngeal gland of the European honeybee, Apis mellifera. Apidologie 42, 103-116

Hladik, M.L., Vandever, M., Smalling, K.L. (2016) Exposure of native bees foraging in an agricultural landscape to current-use pesticides. Sci. Total Environ. 542, 469-477

Hrassnigg, N., Crailsheim, K. (2005) Differences in drone and worker physiology in honeybees (Apis mellifera). Apidologie 36, 255-277

Human, H., Archer, C.R., du Rand, E.E., Pirk, C.W.W., Nicolson, S.W. (2014) Resistance of developing honeybee larvae during chronic exposure to dietary nicotine. J. Insect Physiol. 69, 74-79

Iwasa, T., Motoyama, N., Ambrose, J.T., Roe, R.M. (2004) Mechanism for the differential toxicity of neonicotinoid insecticides in the honey bee, Apis mellifera . Crop Prot. 23 (5), 371-378

Kasiotis, K.M., Anagnostopoulos, C., Anastasiadou, P., Machera, K. (2014) Pesticide residues in honeybees, honey and bee pollen by LC-MS/MS screening: reported death incidents in honeybees. Sci. Total Environ. 485-486, 633-642

Klein, A.-M., Vaissière, B.E., Cane, J.H., SteffanDewenter, I., Cunningham, S.A., et al. (2007) Importance of pollinators in changing landscapes for world crops. Proc. Biol. Sci. 274 (1608), 303-313

Koch, H., Weißer, P. (1997) Exposure of honey bees during pesticide application under field conditions. Apidologie 28, 439-447
Kubik, M., Nowacki, J., Pidek, A., Warakomskab, Z., Michalczuka, L., Goszczyñski, W. (1999) Pesticide residues in bee products collected from cherry trees protected during blooming period with contact and systemic fungicides. Apidologie 30, 521-532

Moritz, B., Crailsheim, K. (1987) Physiology of protein digestion in the midgut of the honeybee (Apis mellifera L.). J. Insect Physiol. 33 (12), 923-931

Mullin, C.A., Frazier, M., Frazier, J.L., Ashcraft, S., Simonds, R., et al. (2010) High levels of miticides and agrochemicals in North American apiaries: Implications for honey bee health. PLoS One 5(3), 1-19

OECD (2007) Guidance document on the honeybee (Apis mellifera ) brood test under semi-field conditions. No. 75. ENV/JM/MONO(2007)22

Pareja, L., Colazzo, M., Pérez-Parada, A., Niell, S., Carrasco-Letelier, L., et al. (2011) Detection of pesticides in active and depopulated beehives in Uruguay. Int. J. Environ. Res. Public Health 8 (10), 3844-3858

Pilling, E.D., Bromley-Challenor, K.A.C., Walker, C.H., Jepson, P.C. (1995) Mechanism of synergism between the pyrethroid insecticide and the imidazole fungicide prochloraz in the honeybee (Apis mellifera L.) Pestic. Biochem. Physiol. 51 , 1-11

Pistorius, J., Becker, R., Lückmann, J., Schur, A., Barth, M., et al. (2011) Effectiveness of method improvements to reduce variability of brood termination rate in honey bee brood studies under semi-field conditions. 11th International Symposium of the ICP-BR Bee Protection Group, Wageningen. pp. 115-120

PPDB (2016) Pesticide Properties Data Base, University of Hertfordshire. http://sitem.herts.ac.uk/aeru/ppdb/en/ atoz.htm\#A, assessed on 2016 February 18

Robinson, G. (1985) Effects of a juvenile hormone analogue on honey bee foraging behaviour and alarm pheromone production. J. Insect Physiol. 31 (4), 277-282

Rosenkranz, P., von der Ohe, W., Moritz, R.F.A., Genersch, E., Büchler, R., et al. (2013) Schlussbericht, Deutsches Bienenmonitoring. pp. 1-64

Rutz, W., Gerig, L., Wille, H., Lüscher, M. (1976) The function of juvenile hormone in adult worker honeybees, Apis mellifera. J. Insect Physiol. 22 (11), 1485-1491

Samson-Robert, O., Labrie, G., Chagnon, M., Fournier, V. (2014) Neonicotinoid-contaminated puddles of water represent a risk of intoxication for honey bees. PLoS One 9 (12), 1-17

Sanchez-Bayo, F., Goka, K. (2014) Pesticide residues and bees-A risk assessment. PLoS One 9(4), 1-16

Schnier, H.F., Wenig, G., Laubert, F., Simon, V., Schmuck, R. (2003) Honey bee safety of imidacloprid corn seed treatment. Bull. Insectology 56(1), 73-75

Schur, A., Tornier, I., Brasse, D., Mühlen, W., von der Ohe, W., et al. (2003) Honey bee brood ring-test in 2002: Method fort the assessment of side effects of plant protection products on the honey bee brood under semi-field conditions. Bull Insectology 56 (1), 91-96 
Tasei, J. (2001) Effects of insect growth regulators on honey bees and non-Apis bees. A review. Apidologie 32, 527-545

Thompson, H. M. (2003) Behavioural effects of pesticides in bees-Their potential for use in risk assessment. Ecotoxicology 12, 317-330

Thompson, H.M., Fryday, S. L., Harkin, S., Milner, S., et al. (2014) Potential impacts of synergism in honeybees (Apis mellifera) of exposure to neonicotinoids and sprayed fungicides in crops. Apidologie 45, 545-553

Urlacher, E., Monchanin, C., Rivière, C., Richard, F.J., Lombardi, C., et al. (2016) Measurements of chlorpyrifos levels in forager bees and comparison with levels that disrupt honey bee odormediated learning under laboratory conditions. J Chem Ecol 42, 127-138

van Engelsdorp, D., Evans, J.D., Saegerman, C., Mullin, C., Haubruge, E., et al. (2009) Colony collapse disorder: A descriptive study. PLoS One 4 (8), 1-17
Wiest, L., Buleté, A., Giroud, B., Fratta, C., Amic, S., et al. (2011) Multi-residue analysis of 80 environmental contaminants in honeys, honeybees and pollens by one extraction procedure followed by liquid and gas chromatography coupled with mass spectrometric detection. J. Chromatogr. A 1218 (34), 5743-5756

Williams, G.R., Troxler, A., Retschnig, G., Roth, K., Yañez, O., et al. (2015) Neonicotinoid pesticides severely affect honey bee queens. Sci. Rep. 5(14621), 1-8

Williamson, S.M., Moffat, C., Gomersall, M.A.E., Saranzewa, N., Connolly, N., Wright, G.A. (2013) Exposure to acetylcholinesterase inhibitors alters the physiology and motor function of honeybees. Front. Physio. 4 (13), 1-10

Winston, M.L., Dropkin, J.A., Taylor, O.R. (1981) Demography and life history characteristics of two honey bee races (Apis mellifera). Oecologia 48, 407-413

Wu, J.Y., Anelli, C.M., Sheppard, W.S. (2011) Sub-lethal effects of pesticide residues in brood comb on worker honey bee (Apis mellifera) development and longevity. PLoS One 6(2), 1-11 